\title{
Correlation and path analysis between yield and different morphological characters in Kinnow Mandarin (C. Noballis $\times C$. Deliciosa)
}

\section{Geeta Verma*}

Department of Basic Sciences, Dr Y S Parmar University of Horticulture and Forestry, Nauni, Solan - 173230 (Himachal Pradesh), India

P.K. Mahajan

Department of Basic Sciences, Dr Y S Parmar University of Horticulture and Forestry, Nauni, Solan - 173230 (Himachal Pradesh), India

\section{Anju Sharma}

Department of Basic Sciences, Dr Y S Parmar University of Horticulture and Forestry, Nauni, Solan - 173230 (Himachal Pradesh), India

*Corresponding author. E-mail: geetverma57@gmail.com

\section{Abstract}

A study of interrelationship and cause-effect analysis of yield of Kinnow Mandarin ( $C$. Noballis $\times$ C. deliciosa) and its component traits for 104 and 96 trees from Indora (Location L-1) and Indpur (Location L-2) blocks of Kangra district respectively had been done in 2014-15. F-test suggested that there was significant (1.47) variation among yield characteristics between these two locations except for fruit weight ( $\mathrm{gm})$ and LD ratio. Results obtained from path coefficient analysis, showed that for location $\mathrm{L}-1$, number of fruits per branch (0.229), plant height (0.215) and tree girth $(0.212)$ had highest and direct effect on yield per tree whereas for location L-2, fruit weight $(0.38)$, number of flowers per branch (0.176) and plant girth (0.161) had highest direct effect on yield per plant. Thus, number of fruits per branch, number of flowers per branch and tree girth were the most important yield components of kinnow crop which should be exploited through a breeding programme for improving its yield potential.

Keywords: Correlation, Direct effect, Indirect effect, Kinnow Mandarin (C. Noballis $\times C$. deliciosa), Path coefficient analysis, Variability analysis

\section{INTRODUCTION}

The adequate knowledge of association between yield and its contributing traits has a great importance in plant breeding. For any crop, to setup a suitable breeding programme, information about interrelationship among and between yield contributing characters is necessary. Correlation and the path coefficient analysis would provide a true picture of association among different traits (Bhatt, 1973). Path coefficient analysis, simply being a standardized partial regression coefficient, splits the correlation coefficient into the measures of direct and indirect effects (Dewey and Lu, 1959). Path analysis has widely been used by plant breeders to identify traits that are useful as selection criteria to improve yield (Milligan et al., 1990; Surek and Beser, 2003).

Correlation coefficients between yield and yield components and direct and indirect effects of various plant characters on yield and yield components have been reported by Muhammad et al. (2002); Atta et al. (2008) and Padmavathi et al.

\section{Article Info}

DOI:10.31018/jans.v10i2.1774

Received: November 27, 2017

Revised: April 17, 2018

Accepted: May 15, 2018

\section{How to Cite}

Verma, G. et al. (2018) Correlation and path analysis between yield and different morphological characters in Kinnow Mandarin (C. Noballis $\times$ C Deliciosa). Journal of Applied and Natural Science, 10(2): $759-764$
(2013). The present research was conducted to study inter- relationships among yield and its contributing traits of Kinnow Mandarin (C. Noballis $\times$ C. Deliciosa)

\section{MATERIALS AND METHODS}

Field experiments were conducted during 2014-15 at farmers' orchard s in Indora (L-1) and Indpur (L2) blocks of Kangra district being the main kinnow growing belt of the Himachal Pradesh. A random sample of 104 and 96 trees from location L-1 and location $L-2$ respectively, was selected following a two-step approach as suggested by Stein (1945) and Cox (1958). According to this approach, in the first step, a small sample of size $n_{1}$ is selected. Observations made on the units selected in this sample, are used to estimate various parameters involved in the expression for the half width of the confidence interval. After replacing the parameters by their respective estimates obtained from the preliminary sample, half width of the confidence interval are equated to the permissible error $\mathrm{B}$. The equation is then solved for $n$, the required 
Verma G. et al. / J. Appl. \& Nat. Sci. 10 (2): 759 - 764 (2018)

sample size. If $\mathrm{n}>\mathrm{n}_{1}$, then $\left(\mathrm{n}-\mathrm{n}_{1}\right)$ additional units are selected, which along with the preliminary sample yield a pooled sample of $n$ units. If $n<n_{1}$, no more units are selected and preliminary sample is taken as the final sample. After selecting the samples, observations on yield per tree $(Y)$, plant girth $\left(X_{2}\right)$, plant spread $\left(X_{3}\right)$, number of leaves per branch $\left(X_{4}\right)$, annual shoot extension growth $\left(X_{5}\right)$, number of flowers per branch $\left(X_{6}\right)$, number of fruits per branch $\left(X_{7}\right)$, fruit weight $\left(X_{8}\right)$, fruit set $\left(X_{9}\right)$ and Length $x$ Diameter $(L D)$ ratio $\left(X_{10}\right)$ were recorded. For calculating the Spread of the tree, average of East-West $\left(\mathrm{X}_{3 \mathrm{E}}\right)$ and North-South $\left(\mathrm{X}_{3 \mathrm{~W}}\right)$ Spread was taken. From each of the selected trees, four branches were chosen randomly from each of four directions and observations on Number of leaves per branch, flowers and fruits per tertiary branch were recorded. Average values of these variables were taken for further analyses. The data so collected were subjected to correlation and path coefficient analysis.

Estimation of correlation: Yield is a complex character and is determined by many component characters. The identification of important characters and their interrelationship would be useful for developing improved trait. Thus, effective improvement in yield may be brought about through selection based on yield component characters. Correlation analysis for fruit yield provides opportunity for selection and leads to a directional model based on yield and its components in field experiments (Khan and Qureshi, 2001). Therefore, correlation study was carried out and correlation coefficient was estimated according to Prasad and Rao (1989).

Estimation of path coefficient: Path coefficient analysis is a technique of statistical analysis specially designed to quantify direct and indirect trait association with yield. When more characters are involved in correlation study it becomes difficult to ascertain the characters which significantly contribute to yield. The path coefficient analysis under such situations helps to determine the direct contribution of these characters and their indirect contributions via other characters. Hence, using correlation values, path coefficient analysis was carried out by following the procedure given by Dewey and Lu (1959) in which correlation co-efficient is partitioned into direct and indirect effects of independent variable(s) on the dependent variable. The estimated values were compared with table values of correlation coefficient to test the significance of correlation coefficient prescribed by Fisher and Yates (1967).

Procedure for setting up the simultaneous equations: The path coefficients were obtained by simultaneous selection of the following equations, which expresses the basic relationship between correlation ' $r$ ' and path coefficients $(P)$.

$$
r_{14}=P_{14}+P_{24} \gamma_{12}+P_{34} \gamma_{13}
$$

$$
\begin{aligned}
& r_{24}=P_{14} r_{21}+P_{24}+P_{34} r_{23} \\
& r_{34}=P_{14} r_{31}+P_{24} r_{32}+P_{34}
\end{aligned}
$$

where, $r_{14}, r_{24}$ and $r_{34}$ are correlations of different morphological characters with yield (dependent character) and $r_{12}, r_{13}$ and $r_{23}$ are the correlations among independent characters.

The direct effects and indirect effects were obtained by using the matrix methods.

The direct effect was obtained by following set of equations:

$$
\begin{aligned}
& P_{14}=C_{11} r_{14}+C_{12} r_{24}+C_{13} r_{34} \\
& P_{24}=C_{21} r_{14}+C_{22} r_{24}+C_{23} r_{34} \\
& P_{34}=C_{31} r_{14}+C_{32} r_{24}+C_{33} r_{34}
\end{aligned}
$$

where, $\mathrm{C}_{11}, \mathrm{C}_{22}, \mathrm{C}_{23}$ and $\mathrm{C}_{33}$ are constants and $\mathrm{r}_{12}$ $P_{24}, r_{13} P_{34}, r_{21} P_{14}, r_{23} P_{34}, r_{31} P_{14}, r_{32} P_{24}$ are indirect effects.

Residual effect: The variation in the dependent variable which remained undetermined by including all the variables was assumed to be due to the variables not included in the present investigation. The degree of determination of such variable (s) on dependent variable was calculated as follows:

$$
1=P_{1} X_{42}+P_{2} X_{42}+P_{3} X_{42}+2 P_{14} r_{12} P_{24}+2 P_{14} r_{13} P_{34}+2 P_{24} r_{23} P_{34}
$$

\section{RESULTS AND DISCUSSION}

The data were collected on randomly selected trees from two locations viz. Indora (L-1) and Indpur (L-2) in 2014-15 for various tree growth characteristics viz. plant girth $(\mathrm{cm})$, plant height $(\mathrm{m})$, plant spread $(\mathrm{m})$, number of leaves per branch, annual shoot extension growth $(\mathrm{cm})$, number of flowers per branch, number of fruits per branch, fruit weight $(\mathrm{gm})$ and yield per tree $(\mathrm{kg})$ were subjected to various statistical measures viz. Mean, fiducial limit and coefficient of variation (Table 1). All the replicated data obtained from the experiments for consecutive two locations of study were statistically analysed using the F-test as per the procedure given by Gomez and Gomez (1984). For location L-1, mean fruit yield per plant was $24.63 \mathrm{~kg}$ with 95 per cent fiducial limit 22.6826.58 whereas for location L-2, mean fruit yield was $25.27 \mathrm{~kg}$ with 95 per cent fiducial limit 23.5026.84. F-test suggested that there was significant (1.47) variation among different morphological tree growth characteristics between these two locations except for fruit weight and LD ratio. This variation may be attributed to soil and fertility factors as well as hydro regime strata of the locality affecting microclimate at the growing stages.

Correlation studies and path coefficient analysis: Knowledge of correlation alone is often 
Verma G. et al. / J. Appl. \& Nat. Sci. 10 (2): 759 - 764 (2018)

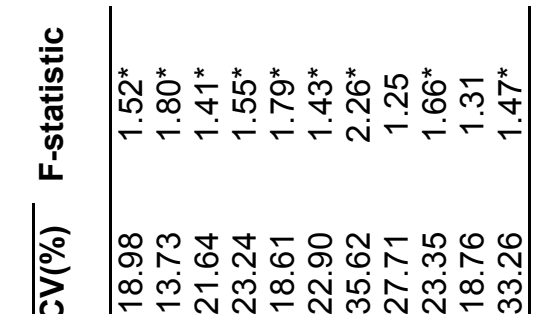

产

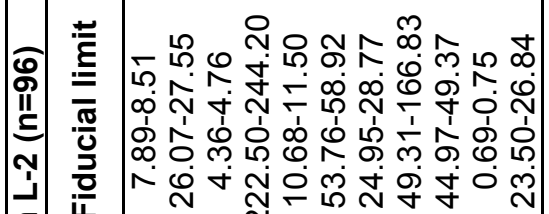

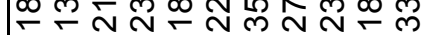

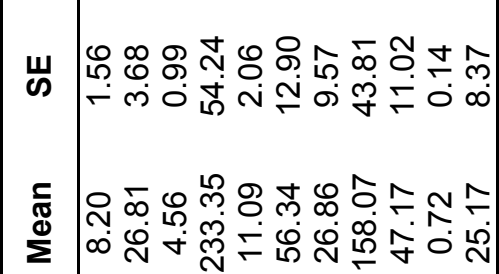

๑

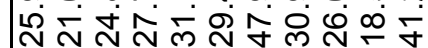

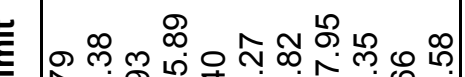

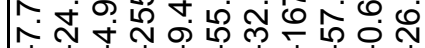

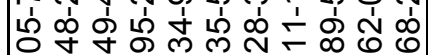
ก ส่

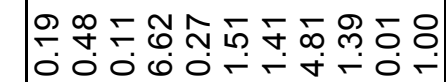

นุ.

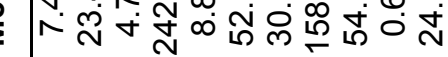

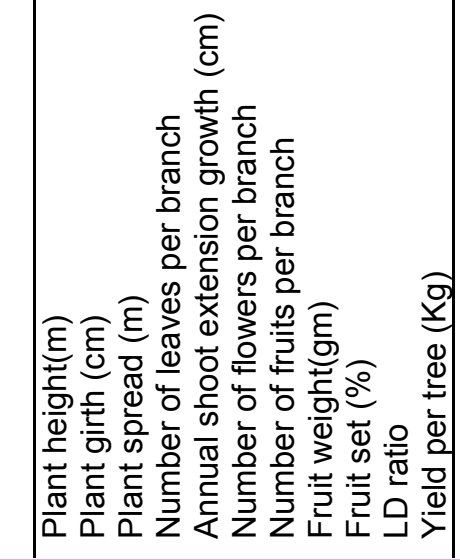

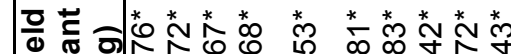

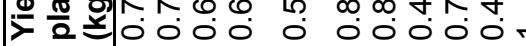

西

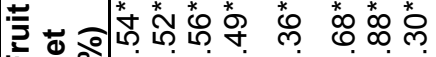

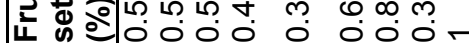

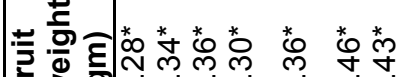

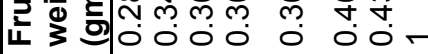

$\div$

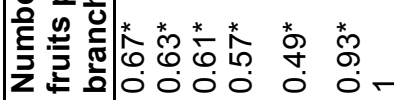

\section{응}

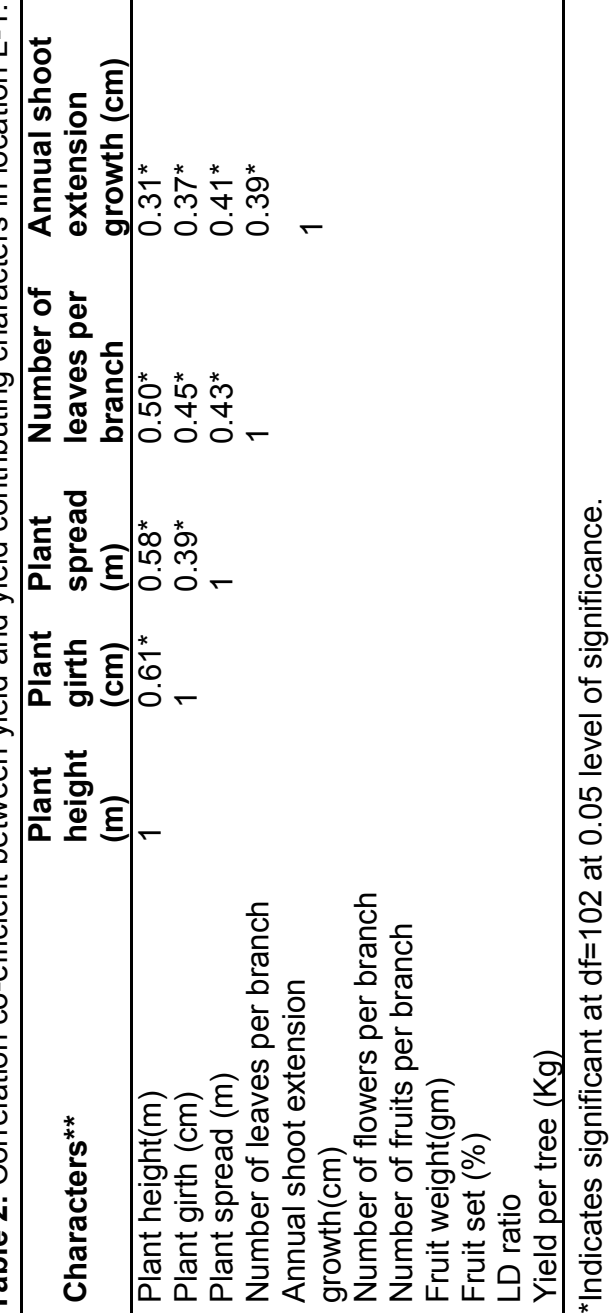


Verma G. et al. / J. Appl. \& Nat. Sci. 10 (2): 759 - 764 (2018)
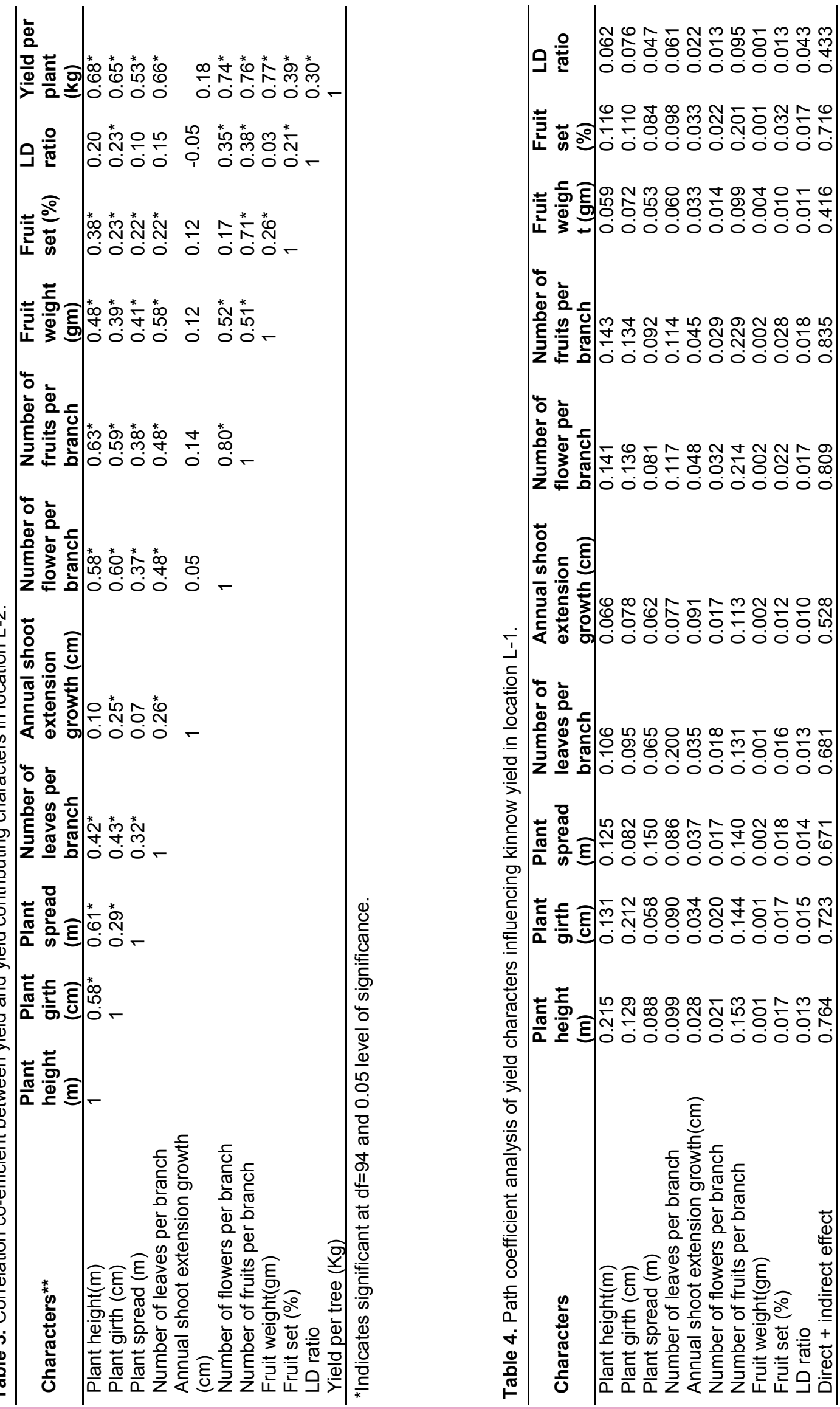


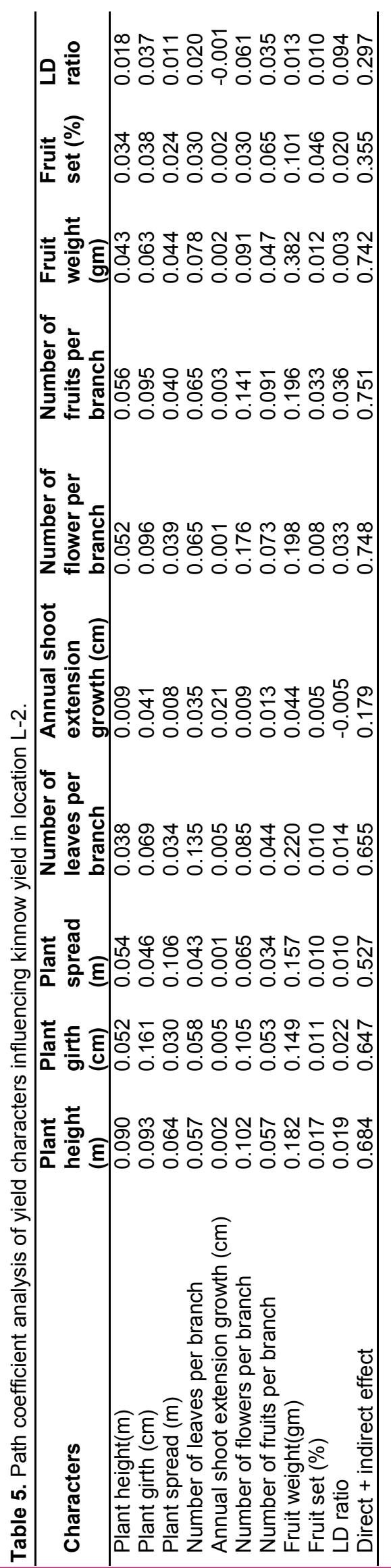

misleading as the correlation observed may not be always true. Two characters may show correlation just because they are correlated with a common third one. In such cases, it becomes necessary to use a method which takes into account the casual relationship between the variables, in addition to the degree of such relationship. Path coefficient analysis measures the direct influence of one variable upon the other, and permits separation of correlation coefficients into components of direct and indirect effects. Portioning of total correlation into direct and indirect effects provide actual information on contribution of characters and thus form the basis for selection to improve the yield (Khan and Dar, 2010).

The Table 2 shows correlation coefficients for location L-1. It appears that yield had positive and significant correlation with number of fruits per branch $(0.83)$ followed by the number of flowers per branch (0.81), plant height (0.76). This suggests that there was strong inherent relationship between the traits contributing towards the yield. It is evident that number of flowers per branch had highest and significant correlation (0.93) with number of fruits per branch. Majumder et al. (2012), also support the results of the present study. The results also showed that there were positive and significant correlation between number of fruits per branch with fruit set $(0.88)$ followed by number of flowers per branch (0.68) and plant spread (0.56). From path coefficient analysis for location, L-1 (Table 4) indicated that the number of fruits per branch had maximum positive direct effect 0.229 on yield per plant. This implies that the selection of these traits (number of fruits per branch) would give better response in yield followed by plant height $(0.215)$ and plant girth (0.212). While maximum positive indirect effect on yield was assessed by number of flowers per branch $(0.214)$ via number of fruits per branch. The least indirect contribution to kinnow yield was via fruit weight followed by LD ratio. There was no direct and indirect negative effect of different traits towards yield. Results are in close agreement with Reddy et al. (2013) and Singh et al. (2013).

The correlation coefficients for location L-2 were calculated and presented in Table 3 . It is evident that most of the characters were highly correlated with yield per tree. The results showed that fruit yield per tree had positive and significant correlation with fruit weight $(0.77)$ followed by number of fruits per branch (0.76), flower per branch (0.74), plant height (0.68), annual shoot extension growth (0.66), plant girth (0.65) and plant spread (0.53). This indicates that the results of correlation studies between yield and yield contributing characters were significant for most of the characters under study and had strong inherent relationship among them. Therefore, selection for any of these traits would offer the scope for simultaneous 
improvement of contributing characters in addition would be helpful in improving the yield potential in kinnow mandarin. Moreover, it is noticeable that yield was positively related with number of leaves per branch (0.18) although not significant. The perusal of path coefficient analysis (Table 5) for location L-2 showed that fruit weight had maximum positive direct effect (0.382) on yield followed by number of flowers per branch (0.176) and plant girth $(0.161)$. The maximum positive indirect effect on yield was observed from annual shoot extension growth (0.22) via fruit weight. In contrast, indirect negative effect of number of leaves per branch $(-0.005)$ through LD ratio and LD ratio $(-0.001)$ via number of leaves per branch was observed. That means simultaneous selection for the characters might be effective in the improvement of fruit yield. Saha (2004) found maximum positive direct effect for average weight of flower on yield in lemon. Residual effects indicating the contribution of other factors on the variability other than the studied ones for location L-1 and location L-2 were calculated to be 0.37 and 0.39 , respectively.

\section{Conclusion}

Karl Pearson's correlation coefficient was worked out between kinnow yield and various morphological characters and results showed that yield per tree had positive and significant correlation with all morphological characters for location L-1, while for location L-2, fruit yield per tree had positive and significant correlation with fruit weight $(0.77)$ followed by number of fruits per branch (0.76), number of flowers per branch (0.74). The use of simple correlation analysis cannot fully explain the relationships among different characters. Therefore, path coefficient analysis has been used by many researchers for a complete determination of the impact of different independent variables on dependent variable. It was observed that in location L-1, the number of fruits per branch had maximum positive direct effect (0.229) on yield per plant followed by plant height $(0.215)$ and plant girth (0.212). In contrasts, it was also observed that maximum positive indirect effect on yield was assessed by number of flowers per plant (0.214) via number of fruits per branch. For location L-2, the result showed that fruits weight had maximum positive direct effect $(0.382)$ on yield followed by number of flowers per branch (0.176), plant girth (0.161), whereas maximum positive indirect effect on yield was observed from annual shoot extension growth (0.22) via fruit weight, but LD ratio via number of leaves per branch were negatively correlated with kinnow yield. The path coefficient analysis helps the breeder to explain direct and indirect effects which have been extensively used in breeding works.

\section{REFERENCES}

Atta, B. M., Muhammad, A. H. and Tariq, M. S. (2008). Variation and Inter Relationships of Quantitative Traits in Chickpea (Cicer Arietinum L.). Pak. J. Bot., 40(2): 637-647.

Bhatt, G.M. (1973). Significance of path coefficient analysis in determining the nature of character association. Euphytica. 2: 338-343.

Cox, D. R. 1952. Estimation by double sampling. Biometrika. 39: 217-227.

Dewey, D. R. and Lu, K.H. (1959). A correlation and path-coefficient analysis of components of crested wheatgrass seed production. Agronomy Journal. 51: 515-518.

Fisher, R. A. and Yates, F. (1967). Statistical tables for Biological, Agricultural and Medical Research, Longmen Group Ltd., London.

Gomez, K.A., Gomez, A.A. (1984). Statistical Procedures for Agricultural Research. Second Edition. John Wiley \& Sons, New York, USA.

Khan, M. H. and Dar, A. N. (2010). Correlation and path coefficient analysis of some quantitative traits in wheat. African Crop Science Journal. 18(1): $9-1$

Khan, M., \& Qureshi, S. (2001). Path Coefficient and Correlation Analysis Studies on Variation Induced by Gamma Irradiation in M1 Generation of Chickpea (Cicer arietinum L.). OnLine Journal of Biological Sci., 3: 108-110.

Majumder, D. A. N., Hassan, L., Rahim, M. A. and Kabir, M. A. (2012). Correlation and path coefficient analysis of mango (Mangifera indica L.). Bangladesh Journal of Agriculture Research, 37 (3): 493-503.

Milligan, S. B., Gravois, K. A., Bischoff, K. P. and Martin, F. A. (1990). Crop effects on genetic relationships among sugarcane traits. Crop Sci., 30: 927-931

Muhammad, S., Hammad, N. M., Rehmat, K., Muhammad, J., \& Kashif, S. 2002. Interrelationships and Path Analysis of Yield Attributes in Chick Pea (Cicer arietinum L.). International Journal of Agriculture \& Biology, 4(3): 404-406.

Prasad, M. B. N. V. and G. S. P. Rao. (1989). Genetic variability, correlations and path- coefficient analysis for some morphological and biochemical constituents of acid lime fruit. Scientia Hort., 41: 43-53.

Reddy, G. E., Suresh, B. G., Sravan, T. and Reddy, P. A. (2013). Interrelationship and cause-effect analysis of rice genotypes in north east plain zone, The Bioscan. 8(4): 1141-1144.

Saha, P. 2004. Performance of some Lemon Germplasm and their Morphological and Molecular Characterization using Isozyme. M.Sc.. Thesis. Dept. of Plant Breeding and Genetics, Bangladesh Agricultural University, Mymensingh, Bangladesh. p. 119.

Singh, C. M., Suresh B. G., Kumar B. and Mehandi, S. (2013). Analysis of quantitative variation and selection criteria for yield improvement in exotic germplasm of upland rice (Oryza sativa L.). The Bioscan., 8(2): 485-492.

Stein, C. (1945). A two sample test for a linear hypothesis whose power is independent of the variance. Annals of the Institutes of Statistical Mathematics, 16: 243-258.

Surek, H. and Beser, N. 2003. Correlation and path coefficient analysis for some yield-related traits in rice (Oryza sativa L.) under thrace conditions. Turk. J. Agric. For., 27: 77-83.

Padmavathi, V., Sreemannarayana, S., Satyanarayana, V., \& Lal, A. (2013). Correlation and Path Coefficient Analysis in Kabuli Chickpea (Cicer Arietinum L.). International Journal of Applied Biology and PharmaceuticalTechnology,4(3): 107-110. 